\title{
ETHNOBIOLOGY OF NORTHEASTERN TURTLE ISLAND FOOD \& MEDICINE: SUMMARY OF AN NSIS LECTURE ${ }^{1}$
}

\author{
JONATHAN FERRIER* \\ Department of Biology, Dalhousie University, Halifax, NS \\ Board of Education, Mississaugas of the \\ Credit First Nation, Hagersville, ON
}

\begin{abstract}
Food, medicine, and material culture are related topics. Securing access requires a respect for the natural laws of the environment. With examples from the Mississaugas of the Credit First Nation (in Ontario), Mi'kmaq First Nation, and global indigenous nations, we observe that indigenous peoples are natural leaders for achieving an ecological balance with our oral stories that document our traditional observations for millennia. Indigenous spirituality and ecological ways of knowing provide solutions for dealing with climate change, local food, medicine, and material security.

With ethnobiology, we awaken native linguistic knowledge, traditions in medicine and foods, and discover designs that were laid dormant by colonization. Native languages and verbal traditions in science carefully described a holistic role that applies to the land, while acknowledging all our relationships with water, plants, medicines, fish, flyers and crawlers, emphasizing their importance to all.
\end{abstract}

\section{SUMMARY OF LECTURE}

Dr. Ferrier began his story by recognizing that we are in Mi'kma'ki, the country and home of the Mi'kmaw and the home that provides food, medicines and material wealth for all inhabitants, which also inspires the Mi'kmaq language. The Proceedings of the NSIS was also where he published his first scientific paper. He has published three papers in the journal during his career (see References). These publications are valuable contributions to the botany in Nova Scotia (Mi'kma'ki) and demonstrate the value of the Proceedings for Nova Scotian science.

1 This was an NSIS Public Lecture on Monday, November 4, 2019. A drumming ceremony was performed by Jonathan and Kirsten Edwards prior to the start of the lecture.

* Author to whom correspondence should be addressed: jferrier@dal.ca, BoardEd.JonathanF@mncfn.ca

Also see www.researchgate.net/profile/Jonathan_Ferrier 
In February, he began his new role as Assistant Professor at Dalhousie University. He has been busy writing and editing a biology textbook, as well as setting up his new lab that focuses on applications of metabolomics, ethnobotany and indigenous studies. During his presentation, Jonathan summarized his work using Nuclear Magnetic Resonance (NMR) to study metabolic processes in local medicinal plants, especially those of his native roots from the Mississaugas of the Credit First Nation. He has been examining blueberry (also called "miinan") extracts that may have potential applications for treating preeclampsia ("a pregnancy complication characterized by high blood pressure and signs of damage to another organ system, most often the liver and kidneys" - Mayo Clinic website).

Dr. Ferrier offered a reframing of science by providing an overview of colonial history. Another aspect of his research focuses on ancestral migration landscapes of Mississauga of the Credit First Nation along the Credit River (Missinnihe "the Trusting Creek") to Eramosa township ("Animoshag" "Group of Dogs") and the Grand River, both in Ontario. A study of colonial history revealed a move away from Anishinaabek migration life history and the sustainable balanced relationships with the natural environment.

The reframing of colonial history provides much to reflect upon, including the destruction caused by saw-mills in the 19th century, and problematic relationships of indentured indigenous workers his family on farms in the territory of the Mississauaga of the Credit First Nation. Dr. Ferrier offered insights about how the indigenous languages and names of regions within Mi'kma'ki offer more of these descriptions of ecological knowledge. The indigenous languages are a blueprint for solving many climate issues. Respecting indigenous languages in indigenous countries inhabited by Canada give us another set of solutions, previously not considered by the dominant culture.

Through application of modern techniques, including LIDAR, digital census records, Nuclear Magnetic Resonance (NMR) metabolomics and other molecular techniques, Dr Ferrier has focused on ethnobotany topics. He is bringing attention to important topics and issues as we move toward decolonization in order to speak the truth and reconcile our history. 


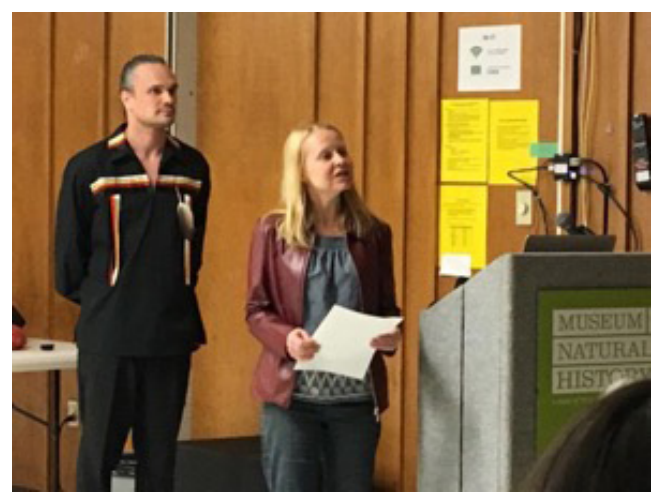

Fig 1 Dr. Tana Worcester (NSIS President) introduces Dr. Jonathan Ferrier during his public lecture.

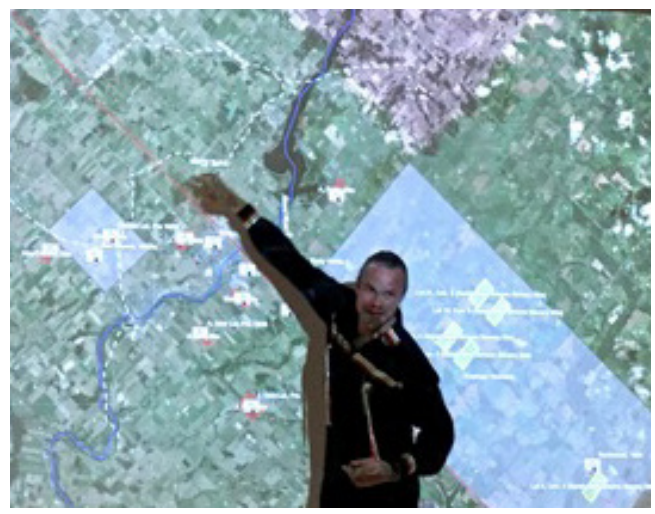

Fig 2 Dr. Jonathan Ferrier points to areas in his family and kin's ancestral lands around the Credit River Valley.

Note: Tana Worcester, NSIS President, stated after the presentation that "We should continue to find ways to facilitate this dialogue between science practiced by western and indigenous people, and the ways we talk about the issues that we face - how they came to be and how we can work together to solve them. That is two-eyed seeing - eduaptmunk" 
